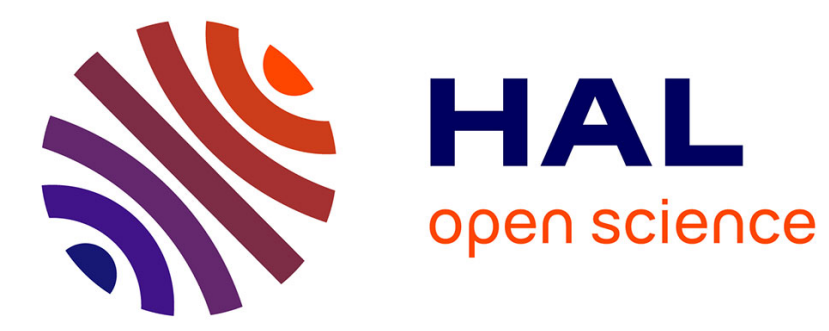

\title{
Approaches to oxidation-resistant refractory metal alloys
}

\author{
I. Wright, V. Nagarajan
}

\section{To cite this version:}

I. Wright, V. Nagarajan. Approaches to oxidation-resistant refractory metal alloys. Journal de Physique IV Proceedings, 1993, 03 (C9), pp.C9-151-C9-157. 10.1051/jp4:1993913 . jpa-00252350

\section{HAL Id: jpa-00252350 https://hal.science/jpa-00252350}

Submitted on 1 Jan 1993

HAL is a multi-disciplinary open access archive for the deposit and dissemination of scientific research documents, whether they are published or not. The documents may come from teaching and research institutions in France or abroad, or from public or private research centers.
L'archive ouverte pluridisciplinaire HAL, est destinée au dépôt et à la diffusion de documents scientifiques de niveau recherche, publiés ou non, émanant des établissements d'enseignement et de recherche français ou étrangers, des laboratoires publics ou privés. 


\title{
Approaches to oxidation-resistant refractory metal alloys
}

\author{
I.G. Wright and V. Nagarajan \\ Battelle, 505 King Avenue, Columbus, Ohio 43201, U.S.A.
}

\begin{abstract}
The focus of the research reported here was on the design of high-temperature alloys which would form protective $\mathrm{SiO}_{2}$ and $\mathrm{Al}_{2} \mathrm{O}_{3}$ scales on exposure to high-temperature, oxidizing environments. One way to promote the growth of such scales is to incorporate sufficient amounts of $\mathrm{Si}$ or $\mathrm{Al}$ in the alloy substrate; typically, additions of approximately 35 to 45 weight percent (all alloy compositions are given in weight percent unless explicitly stated otherwise) of $\mathrm{Si}$ or $\mathrm{Al}$ would be required to form the respective scales, in the absence of additional protective-scale-forming elements. At such levels of alloying additions, the formation of intermetallic phases is likely, which may have undesirable features such as low melting temperatures or poor mechanical properties. The research described was an attempt to address these problems from a fundamentally different point of view, for $\mathrm{Mo}$ - and $\mathrm{Nb}$-based alloys, through the use of a dispersed reservoir phase.
\end{abstract}

\section{Introduction.}

The Wagner criterion [1] for the formation of an external oxide scale on alloy $A B$ requires the mole fraction of $\mathrm{B}\left(N_{\mathrm{B}}^{*}\right)$ needed in the alloy to allow external scale formation to be reduced to its lowest possible value. This can be achieved by minimizing the oxygen permeability of the alloy, or by increasing the diffusivity of the desired element $\left(D_{\mathrm{B}}\right)$. The dispersed reservoir phase approach [2-4] is an attempt to effectively increase $D_{\mathbf{B}}$ by introducing local sources of $\mathrm{B}$, and physically reducing the area to be covered by the $\mathbf{B O}_{m}$ oxide. This approach is based on previous research [5] with a binary Co-25Cr and ternary Co-25Cr-C alloys, which contained sufficient $\mathrm{G}$ to precipitate virtually all the $\mathrm{Cr}$ in the alloy as carbides. In the ternary alloy, the chromium carbides acted as local reservoirs of $\mathrm{Cr}$, and effectively concentrated the desired element $(\mathrm{Cr})$ in the location required for scale formation, and reduced the distance that the Cr must diffuse to the required site. The use of a dispersed reservoir was further demonstrated using $\mathrm{SiC}$ in $\mathrm{Ni}$ to allow the formation of a protective silica scale $[2,4]$.

A generalized application of this approach to the design of oxidation-resistant alloys requires the selection of reservoir phases which are thermodynamically stable in the alloy, but are unstable in the presence of oxygen. Therefore, a detailed thermodynamic analysis of all the possible reactions between the reservoir phase and the constituents of the matrix alloy is a prerequisite.

\section{Experimental procedures.}

The composition of the Mo-based alloy was chosen from the results of prior experimentation [3] that indicated the possibility of forming a continuous $\mathrm{SiO}_{2}$ scale if Mo contained $15 \mathrm{Si}_{3} \mathrm{~N}_{4}$ (30 volume percent) and $6 \mathrm{Si}$. The size range of the starting powders was: $\mathrm{Mo}-2$ to $4 \mu \mathrm{m}$, 
$\mathrm{Si}_{3} \mathrm{~N}_{4}-0.3 \mu \mathrm{m}$, and Si-approximatelly $10 \mu \mathrm{m}$. These powders were milled in a very high energy ball mill to obtain the desired microstructures, and compacted by vacuum-hot-pressing. $\mathrm{A}$ series of $\mathrm{Nb}-\mathrm{Al}$ alloys, using AlN as the dispersed reservoir, and with additional $\mathrm{Al}$ added as $\mathrm{NbAl}_{3}$ up to a total $\mathrm{Al}$ content of approximately 50 weight percent $\left(\mathrm{NbAl}_{3}-20 \mathrm{AlN}\right)$, was prepared by high-energy ball-milling of $\mathrm{Nb}, \mathrm{AlN}$, and $\mathrm{NbAl}_{3}$ powders, which had an average particle size of 3.5 and $10 \mu \mathrm{m}$, respectively. The powders were milled using a modified technique which involved the use of powder handling in a Ti-gettered environment to minimize oxygen pickup and loss of AlN through reaction with moisture. The milled powders were consolidated by vacuum-hot-pressing.

The oxidation exposures were carried out in a horizontal tube furnace equipped with an alumina reaction tube, and the specimens were contained in alumina or zirconaia boats. Weight change data were generated by periodically withdrawing the specimens from the furnace.

\section{Results and discussion.}

Mo-Si $\mathrm{N}_{4}$-Si ALLOY. - The weight change data of specimens of the Mo- $15 \mathrm{Si}_{3} \mathrm{~N}_{4}-6 \mathrm{Si}$ alloy, oxidized in air at 1000,1200 and $1400{ }^{\circ} \mathrm{C}$ are shown in figure 1 . All the specimens initially lost weight due to the formation of volatile $\mathrm{MoO}_{3}$, the rate of loss increasing rapidly with increasing temperature. However, after a few hours, the rate of weight loss abruptly stopped, indicating that formation of the volatile $\mathrm{MoO}_{3}$ had been suppressed due to the formation of a protective, solid scale. Figure 2 shows a cross section of a specimen oxidized for 111 hours at $1000^{\circ} \mathrm{C}$. The secondary electron image and $\mathrm{X}$-ray maps for $\mathrm{Si}$ and $\mathrm{O}$ indicate that the solid oxide layer consits of $\mathrm{Si}$ and $\mathrm{O}$, and is presumably silica.

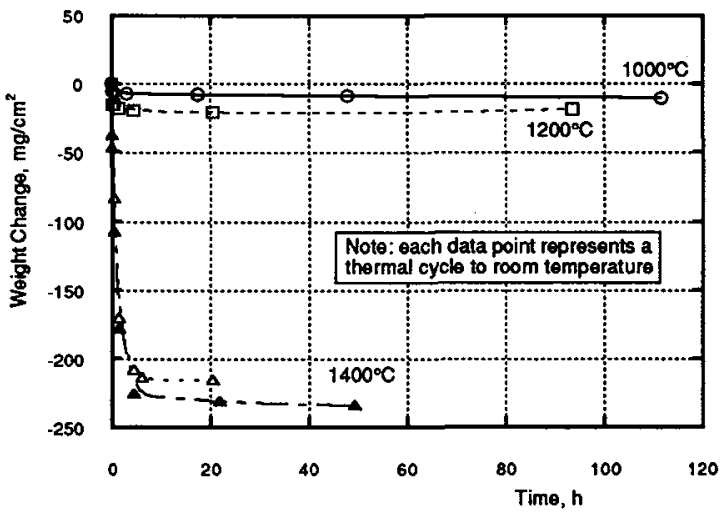

Fig. 1. - Oxidation kinetics of $\mathrm{Mo}-\mathrm{Si}_{-} \mathrm{Si}_{3} \mathrm{~N}_{4}$ alloy in air.

A suggested mechanism for the formation of a protective $\mathrm{SiO}_{2}$ scale on this Mo alloy is shown schematically in figure 3 . The sequence of events that might occur is as follows: at time $t=1$ Mo oxidizes and forms the volatile $\mathrm{MoO}_{3}$. Simultaneously, oxygen dissolves in the Mo and diffuses inward, and $\mathrm{Si}$ and $\mathrm{Si}_{3} \mathrm{~N}_{4}$ particles at the surface oxidize to form $\mathrm{SiO}_{2}$. Also, $\mathrm{Si}$ from the alloy diffuses toward the surface and, where the $\mathrm{Si}$ and $\mathrm{O}$ activities are sufficiently high, 

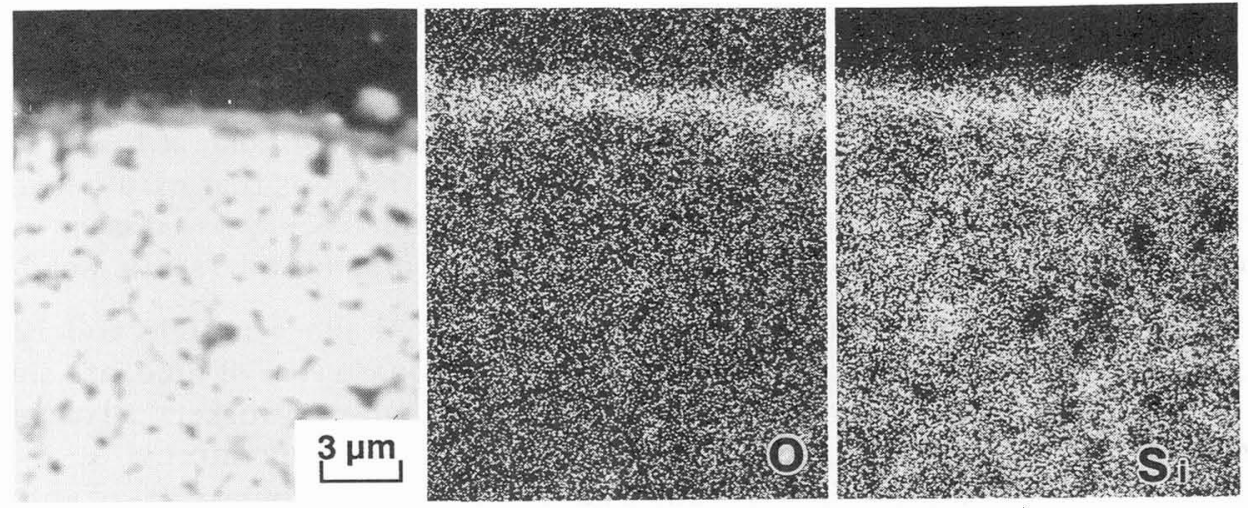

Fig. 2. - Secondary electron image and X-ray maps for silicon and oxygen from a cross section of $\mathrm{Mo}-\mathrm{Si}_{-}-\mathrm{Si}_{3} \mathrm{~N}_{4}$ alloy after oxidation for 111 hours in air at $1000^{\circ} \mathrm{C}$.

High-temperature, oxidizing gas
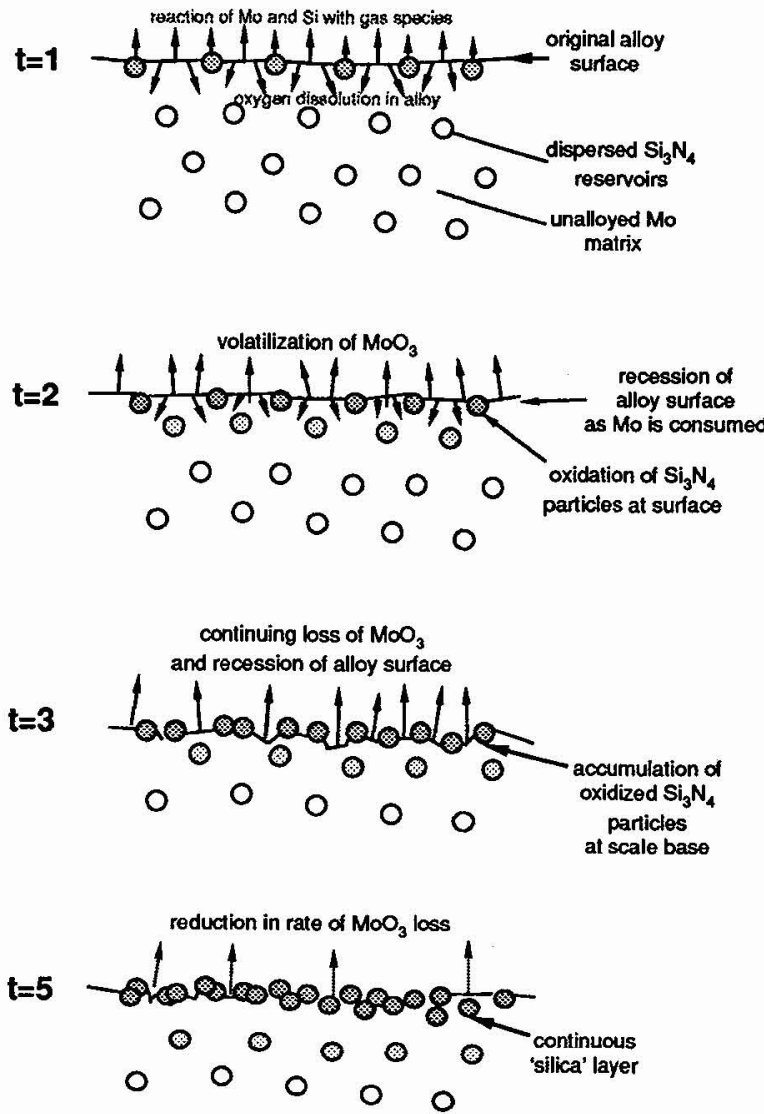

Fig. 3. - Schematic diagram of suggested mechanism of protective scale formation on $\mathrm{Mo}-\mathrm{Si}_{-} \mathrm{Si}_{3} \mathrm{~N}_{4}$ alloy. 
oxidizes to form $\mathrm{SiO}_{2}$. Decomposition of $\mathrm{Si}_{3} \mathrm{~N}_{4}$ is suppressed by the presence of $\mathrm{Si}$ in the alloy. At time $t=2$, volatilization of $\mathrm{MoO}_{3}$ has caused recession of the alloy surface, which in turn causes the oxidized $\mathrm{Si}_{3} \mathrm{~N}_{4}$ particles to accumulate, possibly sintering together. This increasingly dense, blocking layer reduces $\mathrm{O}$ ingress to the alloy so that, at $t=3$, Si in the alloy can diffuse to this layer, where it oxidizes and seals the gaps that exist between the agglomerated $\mathrm{Si}_{3} \mathrm{~N}_{4}$ particles. At $t=4$, an essentially continuous $\mathrm{SiO}_{2}$-based layer has been formed, and the specimen is protected from further oxidation and suffers little weight loss.

Nb-AlN-Al ALLOYS. - The data collected for the Nb-AlN-Al alloys at 1000 and $1200{ }^{\circ} \mathrm{C}$, plotted as weight gain per unit area as a function of the square root of time, are shown in figure 4. In agreement with the previous experience of a number of workers, all of the alloys except $\mathrm{NbAl}_{3}-20 \mathrm{AlN}$ exhibited rapid rates of oxidation at both temperatures.

Metallographic examination of the scales formed indicated voluminous oxides of apparently uniform composition, with no obvious subscale that might be expected to control the oxidation rate.

Further oxidation of the $\mathrm{NbAl}_{3}-20 \mathrm{AIN}$ alloy at 900 and $1400^{\circ} \mathrm{C}$ showed protective behavior at all the temperatures investigated, although the oxidation rate measured at $900{ }^{\circ} \mathrm{C}$ was somewhat faster than that observed at $1200^{\circ} \mathrm{C}$, as is shown in figure 5 . It is not clear whether this change in behavior is inherent in the way this dispersion-containing alloy forms protective scales, but it does not appear to be due to the onset of a pest mechanism. The oxidation rates for this alloy are plotted in a Arrhenius plot, as is shown in figure 6a, which also contains data from the literature $[6,7]$. The best straight line through the experimental points from this work for 1000,1100 , and $1200^{\circ} \mathrm{C}$ gives an activation energy of $114.8 \mathrm{kcal} / \mathrm{mole}$.

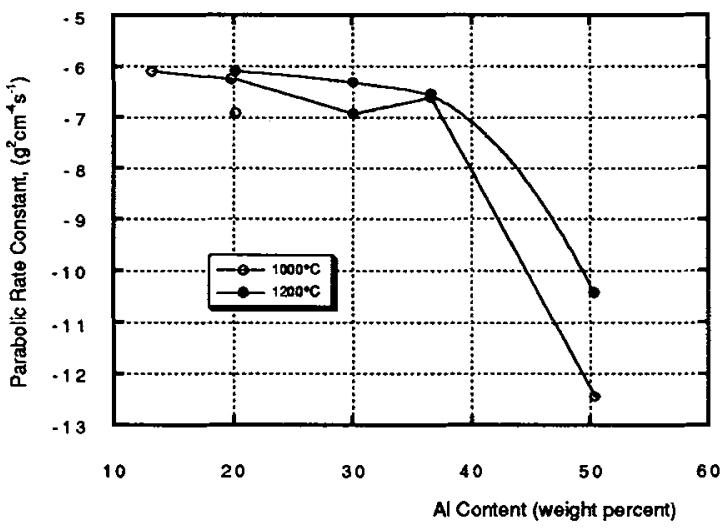

Fig. 4.

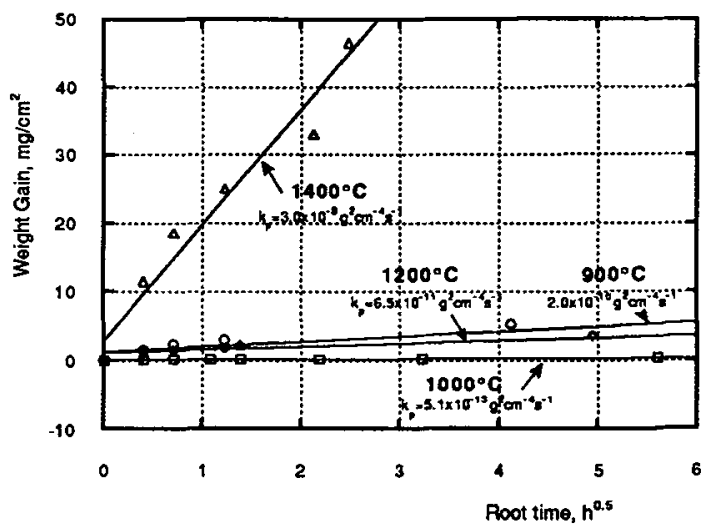

Fig. 5.

Fig. 4. - Effect of aluminum content on oxidation kinetics of $\mathrm{Nb}-\mathrm{Al}$ alloys oxidized in air.

Fig. 5. - Oxidation kinetics of $\mathrm{NbAl}_{3}$-AlN alloy in air at 900 to $1400^{\circ} \mathrm{C}$.

Coincidentally, this value is very close to that cited for oxygen diffusion in single crystal $\mathrm{Al}_{2} \mathrm{O}_{3}$ [8]. Also included in figure $6 \mathrm{a}$ are oxidation data for $\mathrm{Nb}-\mathrm{Ti}-\mathrm{Al}-\mathrm{V}$ alloys in oxygen from the work of Perkins and Meier [10], the triangles representing oxidation rates for these alloys when complex $\mathrm{Nb}-\mathrm{Ti}-\mathrm{Al}$ oxides were formed, while the data points represented by closed circles are oxidation kinetics when these alloys formed a scale of basically protective $\mathrm{Al}_{2} \mathrm{O}_{3}$. 

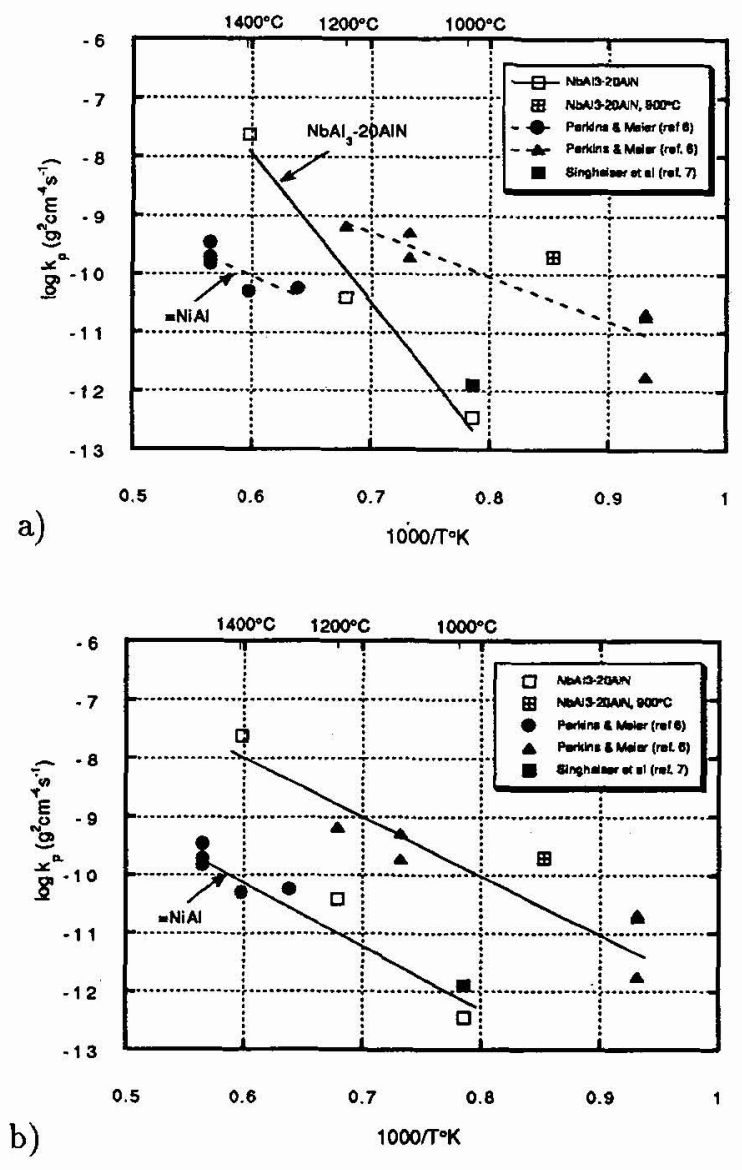

Fig. 6. - Arrhenius plots for oxidation of $\mathrm{NbAl}_{3}-\mathrm{AlN}$ alloy: a) assuming single oxidation mechanism; b) assuming a change in mechanism at $1400^{\circ} \mathrm{C}$.

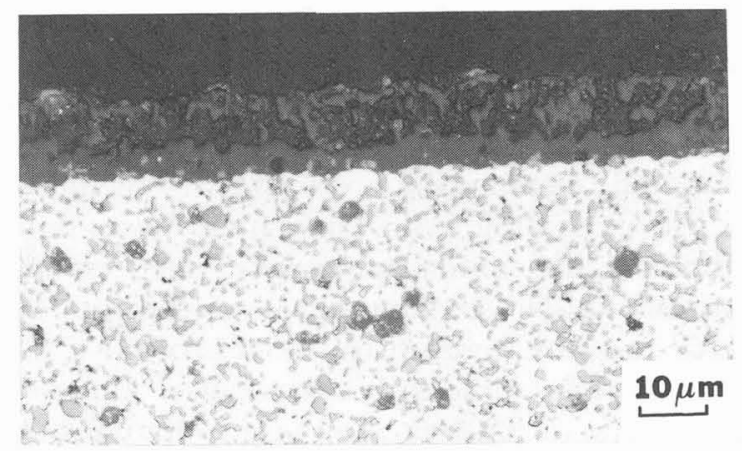

Fig. 7. - Optical cross section of $\mathrm{NbAl}_{3}$-AlN oxidized at $1200^{\circ} \mathrm{C}$. 
The line drawn through these latter points is that representing the rate of oxidation of $\mathrm{NiAl}$, when a reliably protective $\mathrm{Al}_{2} \mathrm{O}_{3}$ scale was formed. The data points generated at 1000 and $1200{ }^{\circ} \mathrm{C}$ in the present work fall very close to this line, while the data point at $1400{ }^{\circ} \mathrm{C}$ is closer to the line representing the formation of complex $\mathrm{Nb}$-Al-containing oxides. This might suggest that the oxidation behavior of the $\mathrm{NbAl}_{3}-\mathrm{AlN}$ alloy is controlled by diffusion through a protectrive $\mathrm{Al}_{2} \mathrm{O}_{3}$ layer at the two lower temperatures, but that at $1400^{\circ} \mathrm{C}$, a continuous alumina scale is not formed, so that the oxidation behavior is then controlled by a complex $\mathrm{Nb}-\mathrm{Al}$-containing scale. Figure $6 \mathrm{~b}$ shows a graphical representation of this interpretation. The suggestion that an $\mathrm{Al}_{2} \mathrm{O}_{3}$ scale is formed at the lower temperatures but not at $1400{ }^{\circ} \mathrm{C}$ is, however, in direct contrast to the behavior of Perkins and Meier's Nb-Ti-Al-V alloys, which were only able to form a continuous $\mathrm{Al}_{2} \mathrm{O}_{3}$ layer at the higher temperatures. Note also that a data point from Singheiser, et al. [7] for the oxidation of $\mathrm{NbAl}_{3}$ at $1000{ }^{\circ} \mathrm{C}$ also falls close to the line for the growth of alumina on NiAl.

Figure 7 shows a metallographically-polished cross section of $\mathrm{NbAl}_{3}-20 \mathrm{AlN}$ after oxidation for 76.5 hours at $1200^{\circ} \mathrm{C}$. The metal-oxide interface appears to be essentially flat, and the two-layered structure of the scale is evident. The inner layer was shown by energy-dispersive $\mathrm{X}$-ray analysis to be enriched in $\mathrm{Al}$. X-ray diffraction analysis indicated that alpha- $\mathrm{Al}_{2} \mathrm{O}_{3}$ was the major phase present. The outer, apparently porous layer was $\mathrm{Nb}$-rich, and presumably represented the transient scale that formed during the time required for the basal layer of $\mathrm{Al}_{2} \mathrm{O}_{3}$ to become continuous. These data appear to confirm that a continuous basal oxide layer of essentially $\mathrm{Al}_{2} \mathrm{O}_{3}$ is formed on this alloy and controls the oxidation rate.

Although unmodified $\mathrm{NbAl}_{3}$ contains sufficient $\mathrm{Al}$ to initially form an $\mathrm{Al}_{2} \mathrm{O}_{3}$ scale, Steinhorst and Grabke [9] have shown that such sacles are rapidly disrupted and that oxidation at a linear rate ensues. This is a result of the formation in the Al-depleted region beneath the scale of the next-lower intermetallic, $\mathrm{Nb}_{5} \mathrm{Al}_{3}$, which oxidizes rapidly once exposed to the environment. Al-rich $\mathrm{NbAl}_{3}$ was demonstrated to form consistently protective scales.

Any explanation of the effects of the dispersed reservoir phase on the development and maintenance of a protective $\mathrm{Al}_{2} \mathrm{O}_{3}$ scale on $\mathrm{NbAl}_{3}$ must account for the facts that, since $\mathrm{Nb}$ oxides grow by anion diffusion, there is no injection of vacancies, nor accumulation of oxidized reservoir particles beneath the outer scale, as in the case of the Ni-SiC alloy [4], and that there is no volatilization to assist the accumulation of dispersoid particles at the alloy surface, as in the case of the Mo-based alloy. In this case, the formation of a protective scale is thought to be strictly controlled by the inital composition of the alloy, and the initial distribution of AlN in the alloy. One possible function of the $\mathrm{AlN}$ reservoir phase in the $\mathrm{NbAl}_{3}-\mathrm{AlN}$ alloy may have been to compensate for the $\mathrm{Al}$ consumed to form the protective scale, and to prevent the degradation of $\mathrm{NbAl}_{3}$ to $\mathrm{Nb}_{5} \mathrm{Al}_{3}$.

The other mode in which a dispersed-reservoir phase has been observed to promote the formation of a protective, external scale on a Ni-SiC alloy is by dissociating ahead of the advancing oxidation front, and releasing the protective scale-forming element to diffuse to the oxidation front. Because of the rapid, initial oxidation rate of the Nb-based alloys, there is probably insufficient time for this mode of protective scale formation to occur. However, after the formation of the initial $\mathrm{Al}-\mathrm{Nb}$-containing scale on the $\mathrm{NbAl}_{3}-\mathrm{AlN}$ alloy, for instance, the effective oxygen partial pressure beneath this semi-protective scale (which will contain incorporated AlN particles) may be sufficiently low to allow AlN particles in the subjacent alloy to dissociate and contribute to the formation of a continuous alumina scale on a local level. 


\section{Conclusions.}

The experimental results reported demonstrate that the ability to form a protective oxide scale can be incorporated into $\mathrm{Mo}$ and $\mathrm{NbAl}_{3}$ by using the dispersed-reservoir approach described. The use of appropriate reservoir phases, for instance, should allow the formation of any of the three practically-useful oxides or, in principle, any other desired oxide, providing the reservoir phase meets the appropriate thermodynamic criteria. However, this ability comes at the price of incorporating into the alloy a dispersion of second phase particles, which has implications for the mechanical properties of the alloy. At the level and size used in earlier work in a Ni-SiC alloy [4], the dispersed particles resulted in a reduction of the room-teperature ductility of the alloy to 3 percent. While the alloys investigated in this program were obviously not optimized in terms of the minimum volume fraction and particle size of the dispersed second phase, their effect on mechanical properties is obviously an important consideration. Further research is required to translate these concepts to the design of practical, high-temperature components, but the underlying principles appear to offer promise.

\section{Acknowledgements.}

The results for the $\mathrm{NbAl}_{3}$ alloy were generated as part of a progam supported by the Naval Air Development Center, Warminster (NADC) under Contract No. N62269-89-C-0252; Mr. M.K. Thomas was the NADC progam monitor. The data for the Mo-based alloy were from studies supported by Battelle. We are very grateful for this support. The experimental work was accomplished by Mr. R.K. Beal, Mr. P.N. Mincer, and Mr. R.D. Smith.

\section{References}

[1] WAGNER C., Z. Elektrochem. 63 (1959) 72.

[2] STRINGER J., WhitTle D.P., WRight I.G., NAGARAJAN V., El DAHSHAN M.E., A Novel Method for Designing $\mathrm{SiO}_{2}$-Forming Alloys, Proc. 8th International Congress on Metallic Corrosion (Dechema, 1981) p. 655.

[3] NaGaRajan V., Wright I.G., Refractory Metal Alloys Having Inherent High Temperature Oxidation Protection, US Patent No. 4,762,557 (August 9, 1988).

[4] Nagarajan V., WRight I.G., STRINGER J., A Dispersed Reservoir Approach to the Development of Protective Scales on High-Temperature Alloys, Proc. 12th International Plansee Seminar (1989) p. 333.

[5] El Dahshan M.E., STRINGer J., Whittle D.P., Cobalt 4 (1974) 86.

[6] Perkins R.A., Meier G.H., J. Met. 42 (8) (1990) 17.

[7] SingheISER L., GRUNLING H.W., SCHNEIDER K., Development of Oxidation-Resistant Alloys on the Base of the Aluminides $\mathrm{NbAl}_{3}, \mathrm{NiAl}$, and NbNiAl, Proc. Fourth COST501 and COST-505 Conference (Kluwer Academic Publishers, 1990) p. 1703.

[8] SAmsonov G.V., The Oxide Handbook (IFI/Plenum Publications, 1973).

[9] Steinhorst M., GrabKe J.H., Mater. Sci. Eng. A120 (1989) 55. 